\title{
Minimizing the Environmental Impact of Industrial Production: Evidence from South Korean Waste Treatment Investment Projects
}

\author{
Olga A. Shvetsova ${ }^{\mathbb{D}}$ and Jang Hee Lee* \\ School of Industrial Management, Korea University of Technology and Education, 1600, Chungjeol-ro, \\ Byeongcheon-myeon, Dongnam-gu, Cheonan-si, Chungcheongnam-do, Cheonan City 31253, Korea; \\ shvetsova@koreatech.ac.kr \\ * Correspondence: janghlee@koreatech.ac.kr
}

Received: 4 April 2020; Accepted: 14 May 2020; Published: 18 May 2020

\begin{abstract}
This research deals with the theoretical and practical issues of investment support activities for industrial waste management in developed countries, based on the example of South Korea. The main goal of this research is the evaluation of waste treatment investment projects and understanding their impact on the development of environmental policies. The problems of forming the sustainable systems for controlling the disposal of industrial wastes are being studied. The authors discuss the practical application of environmental policies and modern technologies of South Korean companies in the field of industrial waste processing. The approaches of waste investment project's evaluation are applied and multi-criteria decision making (MCDM) methods were discussed for various cases and applications. Using MCDM methods, the authors study the effectiveness of investment projects in waste treatment activities in Korea. The analyses of MCDM methods are implemented in this research to provide some instructions on how to effectively apply these methods in waste treatment investment project analyses. Furthermore, the authors propose a combination of multi-criterial selection and interval preferences to evaluate waste treatment projects. The proposed approach improves the method of calculating economic efficiency based on a one-dimensional criterion and sensitivity analysis. The main results of this research perform the investment impact and risk-analysis on the environmental policies development.
\end{abstract}

Keywords: environmental impact; waste management; industrial production; investment project; risk evaluation; multicriterial approach

\section{Introduction}

The rapid industrialization of South Korea has three characteristics: authoritarian state control over the industrial sphere, high economic growth rates due to export heavy industry, and rapid capital accumulation [1,2]. In particular, heavy industry has had a significant impact on the environment. The problems of forming sustainable systems for controlling the disposal of industrial wastes are become more and more apparent in South Korea. Business and government organizations discuss the practical application of environmental policies and modern technologies of Korean companies in the field of industrial waste processing. That is why it is necessary to discover all of the industrial factors which have a strong impact on the environment, and to develop effective models of waste treatment processing. Large industrial complexes involved in heavy industry have strongly polluted the earth, water and air [3]. In the areas that neighbor industrial complexes, sulfur was found on rice leaves, and some elementary school students fainted on the way to school due to toxic gas emitted from factory stacks. The economic development of South Korea was achieved at the expense of the environment. The same process has been followed by most European countries [4]. 
Solid waste was not considered an environmental issue in Korea for a long time. Bekun et al. in 2019, and Paramati in 2018 [5-7], discuss that there was no concern about how much solid waste was generated, and any waste collected from households was dumped in open landfills without regard for environmental hazards. At the same time, the government charged only a fixed amount for household waste disposal services, regardless of how much waste was disposed of. The Korean economic boom over the past few decades has led to a significant increase in solid waste generation. The Korea Institute of Environmental Technology Development in 1996 announced that, in just 20 years, the total amount of municipal solid waste generated per day increased from about 12,000 tons in 1970 to 84,000 tons in 1990 [8]. As the amount of waste increased rapidly, several problems related to waste disposal developed in Korea.

The Republic of Korea officially recycles more than 85 percent of all waste, as stated in a 2017 government study [8]. On the other hand, illegally dumped waste can be found in rural areas of the country. Despite this criticism, the Korean waste management system is quite effective.

According to the 2018 Korea Environmental Review (ECOREA), 10.3 percent of the country's waste (including household and business waste) was disposed of, 6.3 percent was burnt, 82.4 percent was recycled, and 1.0 percent was dumped into the sea. As of 2012, 97.3 percent of construction waste and 76.5 percent of commercial waste was recycled, 14.9 percent of them was buried in landfills, 6.5 percent was burnt, and 2.1 percent dumped into the sea. Moreover, 54.4 percent of designated waste (the term refers to industrial waste) was processed, 16.4 percent was burnt, 23.0 percent was buried and 6.2 percent was treated with other measures (storage) [9]. Even though the percentage of waste processed during incineration or processing is increasing annually, the rate of processing waste generated in landfills and discharges into the ocean is reduced. The reduction in waste discharged into the sea is the result of a ban on the discharge of wastewater, wastewater from food waste, and cattle wastewater into the ocean in 2012-2013; treatment methods for these types of waste have been replaced by incineration or recycling (Figure 1).

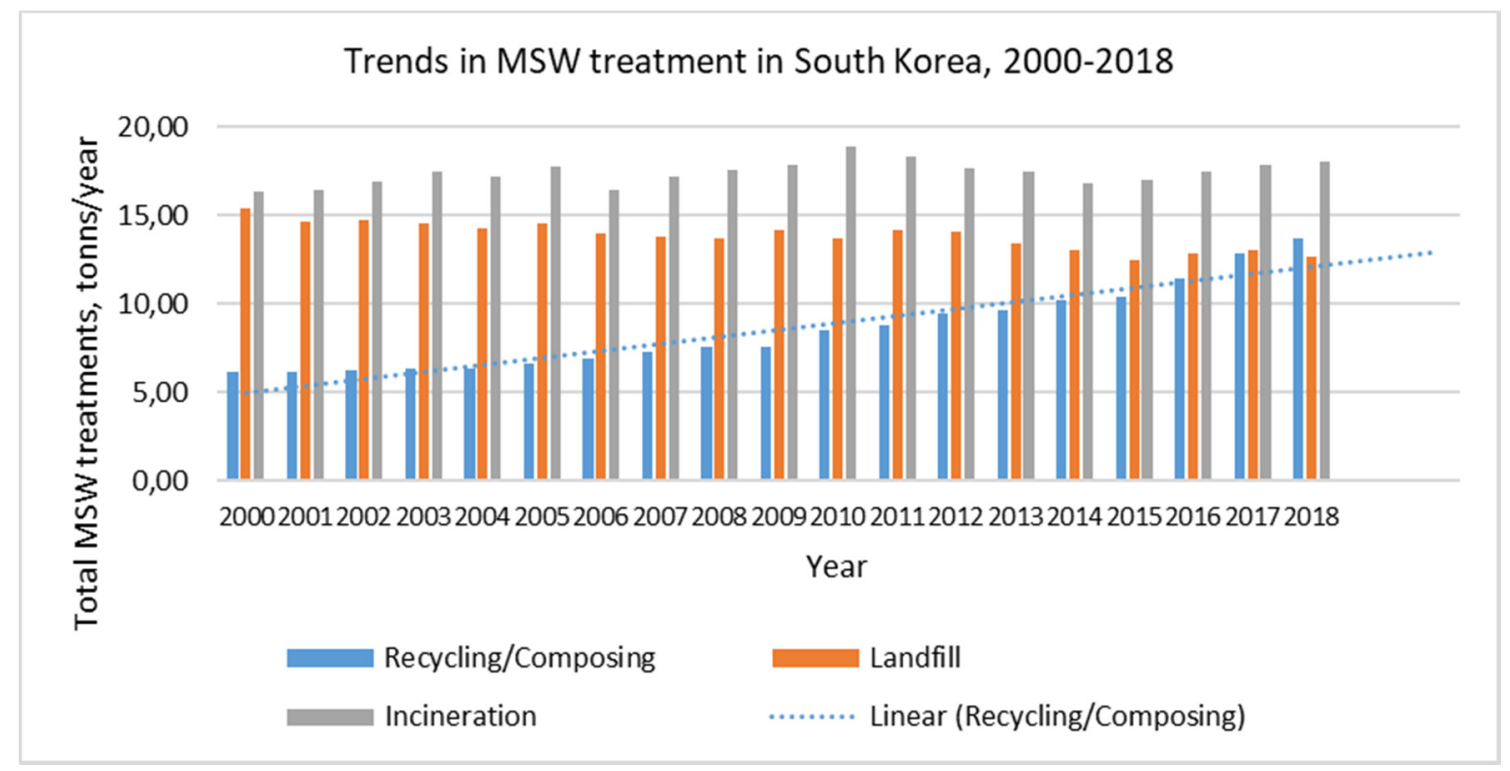

Figure 1. Trends in Municipal Solid Waste treatment in South Korea, 2000-2018. Source: Korea's Environmental Review, 2018, Ministry of Environment, ECOREA, http://eng.me.go.kr [9].

Korea has been one of the fastest growing OECD economies over the past decades, driven by a large export-oriented manufacturing sector [10]. However, growth has come with high pollution and resource consumption. With increasing energy demand, greenhouse gas (GHG) emissions have risen significantly and air pollution remains a major health concern. Despite significant improvements in wastewater treatment, diffuse pollution increasingly affects scarce water resources. Urbanization and 
industrialization also put considerable pressure on biodiversity. The environmental challenges are exacerbated by Korea's population density—the highest in the OECD [11]. Access to environmental goods and services, and exposure to environmental risk vary significantly by region.

To tackle these challenges, Korea has invested considerable effort into improving environmental management, for example, by introducing strategic environmental assessment, reforming the environmental permitting system and strengthening air and water quality standards. Korea introduced the world's second largest emission trading scheme, and remains one of the most innovative countries in terms of climate change mitigation technology. However, coal is set to remain integral to energy production, and road transport continues to be supported as the dominant form of mobility. Current energy prices and taxes do not reflect the environmental costs of energy production and use. The OECD Review Report in 2017 emphasizes that Korea needs to align its energy and climate policies to reduce GHG emissions to $37 \%$ below business-as-usual levels by 2030 [12].

There are many investment projects currently being supported in Korea. Korea's transition to a low-carbon economy is vital for its future prosperity. This is a core message of the OECD report in 2018, which provides 45 recommendations to help Korea pursue the implementation of green growth and strengthen environmental performance [13]. To attain this end, the Korean Government incorporates foreign investment projects in its development of a National Green Strategy. The problem refers to considerations about risk identification for such investment projects, and the further development of waste treatment technologies and methods.

\section{Environmental Policies and Waste Management Methods: Case Study of South Korea}

Starting from 1978, the Korean Government actively enacted comprehensive environmental protection legislation and policies. Since that time, approximately every 10 years, the Korean Environmental Ministry and other government institutions-together with companies-work together to improve environmental policies and develop new technologies for waste treatment. In this section, we discuss the successful waste management methods and regulations in Korea.

\subsection{Waste Management Methods and Environmental Policy in Industrial Production}

Industrialized countries face the challenge of quickly and safely disposing of waste. Non-biodegradable and toxic wastes, such as radioactive residues, can cause irreparable damage to the environment and human health if they are not disposed of strategically.

Although waste management has been a concern for several decades, the main problem has been the enormous proportions of generated waste due to population growth and industrialization - the two main factors contributing to waste generation. Although some successes have been achieved in waste disposal methods, they are still insufficient. The challenge is to discover new and dangerous methods of waste disposal and use them.

Several global companies and local Korean companies (Samsung, CMG, Ovarro, Presona AB, Amandus Kahl GmbH \& Co, Ion Science Ltd., Tana Oy, AMETEK Brookfield and others)—together with leading scientists-have developed a unique technology for processing solid waste $[14,15]$. The latest international developments in the field were combined into a single complex, including the unique technology of catalytic pyrolysis. The uniqueness of this technology is that the garbage is not burned whatsoever. Newly patented in 2013, catalytic pyrolysis makes it possible to completely recycle solid waste without careful sorting measures. It turns waste into valuable commercial products of a high quality and secondary raw materials. Based around the method, a recycling complex of a new type was created. However, the problems of risk-management and cost-analysis of these methods' implementation and operation quickly arose. Nowadays, these companies try to invent new risk-analysis methods within the waste management process to reduce operational costs. The managers understand that project-management concepts help them understand certain basic requirements and cooperative management strategies. 
Innovative technology deserves attention. The complex processing of solid industrial waste in a vortex air-mineral flow-which is based on in-depth study of the chemical, mineral composition and technological properties of the secondary raw materials, and is an individual solution for each type of industrial solid waste with maximum processing efficiency-eliminates the use of water and chemical reagents.

Industrial waste, as it turned out, can be used as a secondary resource in various industries, especially in the production of building materials, products and structures. The main tasks in the field of processing industrial waste should be aimed at improving existing processes, creating and implementing the latest technology. It is necessary to develop and implement measures aimed at implementing waste directly in the manufacturing process.

There are six effective waste disposal methods in South Korea which foreign and domestic companies prefer to venture into:

1. The prevention or reduction of waste: the widespread use of new or unnecessary products is the main reason for the generation of unverified waste. Rapid population growth necessitates reusing products or the judicious use of existing products, as, otherwise, there is a potential risk that people may suffer from the harmful effects of toxic waste. Waste disposal should also take a formidable form. On a personal and professional level, a conscious decision must be made to curb the dangerous increase in waste.

2. Recycling: serves to turn waste into products of its genre through industrial processing. Paper, glass, aluminum and plastic are typically recycled. The environmentally friendly reuse of waste instead of adding it to nature. However, the processing technology is quite expensive.

3. Incineration: incineration involves the incineration of waste, turning it into basic components, and the heat generated is then used to generate energy. Various gases and inert ash are common byproducts. Pollution is caused in varying degrees, dependent on the nature of the waste burned and the design of the incinerator. In 2019, Claborn said that using filters can check for pollution. Waste incineration is relatively inexpensive, and waste is reduced by about $90 \%$ [16]. Nutrient-rich ash obtained from burning organic waste can contribute to hydroponic solutions. Using this method, you can easily get rid of hazardous and toxic waste. The extracted energy can be used for cooking, heating and supplying energy to the turbines. However, strict vigilance and due diligence should be observed to check for the accidental leakage of micro-level contaminants-such as dioxins-from waste incineration lines.

4. Composting: involves the decomposition of organic waste by microbes, allowing waste to accumulate in the pit for a long period of time. In 2018, Freeman suggested that nutrient-rich compost can be used as plant manure [17]. However, the process is slow and takes up a significant amount of land. Biological processing significantly improves soil fertility.

5. Sanitary landfill: This is a landfill for waste. The base is made of a protective lining, which serves as a barrier between the waste and groundwater, and prevents the leaking of toxic chemicals into the water zone. The layers of waste are compacted and then covered with a layer of earth. Non-porous soil is preferred to reduce vulnerability to the accidental leakage of toxic chemicals. In 2017, Wackernagel M. et al. said that landfills should be established in areas with low groundwater levels and away from flood sources. However, a sufficient amount of skilled labor is required to maintain sanitary landfills [18].

6. Disposal in the ocean/sea: waste, usually of a radioactive nature, is discharged into the oceans away from the active human habitat. Nevertheless, environmentalists dispute this method, since it is believed that such an action means death for aquatic life, depriving ocean waters of its natural nutrients.

There is a three-tier approach to assessing the risk associated with air and water emissions from waste management facilities. With this approach, an acceptable level of protection is provided at all levels, but with each progressive level, the level of uncertainty in the risk analysis decreases [19-22]. 
Reducing the level of uncertainty in risk analysis can reduce the level of control required by the waste management unit (if necessary for the site), while maintaining an acceptable level of protection. An enterprise performing a risk assessment incurs higher costs associated with a more complex risk assessment in exchange for greater confidence and potentially lower construction and operating costs. The advantages and relative costs of each tier are outlined below in Table 1.

Table 1. Three-tiered approach for assessing the risk of waste treatment projects.

\begin{tabular}{|c|c|}
\hline Tier & Characteristics (Advantages and Disadvantages) \\
\hline Tier 1 Evaluation & $\begin{array}{ll}\text { - } & \text { Allows for a quick but conservative assessment. } \\
\text { - } & \text { Lower cost. } \\
\text { - } & \text { Minimum site data required. } \\
\text { - } & \text { Assumptions about the fate and transfer of } \\
\text { pollutants and exposure are developed using } \\
\text { conservative assumptions that are not specific } \\
\text { to the sites provided by the EPA. Values are } \\
\text { presented in "look-up tables," which provide a } \\
\text { quick and easy means of assessing risk. These } \\
\text { values are designed for protection in a wide } \\
\text { range of conditions and situations and are very } \\
\text { conservative in design. }\end{array}$ \\
\hline Tier 2 Evaluation & $\begin{array}{l}\text { - } \quad \text { Represents a higher level of difficulty. } \\
\text { - } \quad \text { Moderate cost. } \\
\text { - } \quad \text { Provides the ability to enter some site-specific } \\
\text { data into a risk assessment and, thus, provide a } \\
\text { more accurate picture of the site's risk. } \\
\text { - Uses relatively simplified } \\
\text { fate-and-transport models. }\end{array}$ \\
\hline Tier 3 Evaluation & $\begin{array}{l}\text { - } \quad \text { Provides a sophisticated risk assessment. } \\
\text { - } \quad \text { Higher cost. } \\
\text { - } \quad \text { Allows for the maximum use of specific site } \\
\text { data and, thus, provides the most accurate } \\
\text { picture of the risk of the site. } \\
\text { - Uses more sophisticated fate-and transport } \\
\text { models and analysis. }\end{array}$ \\
\hline
\end{tabular}

Source: adopted from Tonmoy F. N., Rissik D. and Palutikof J. P. A three-tier risk assessment process for climate change adaptation at a local scale. Climatic Change, 153, 2019, pp. 539-557 [22].

We try to solve these practical problems associated with conducting an assessment of the risk of waste management in an organization, and offer a multi-level structure that supports the training path necessary for adaptation, allowing organizations to optimize their resources for adaptation, systematically increase the knowledge base on waste management, and develop targeted interaction strategies.

\subsection{Waste Management Regulations and Environmental Policies in South Korea}

Currently, the regulatory regime for environmental protection in South Korea consists of legislative acts, executive decrees, ministerial decrees and regulatory acts related to the general environment, including:

1. Nature conservation.

2. Preservation of air quality. 
3. Preservation of water quality.

4. Water supply/Sewer management system.

5. Recycling/Waste recycling.

6. Green growth.

The basic framework is laid in the Framework Act on Environmental Policy (FAEP), which contains the main objectives of environmental policy, including pollution prevention and natural resource management for sustainable use. To create such a sustainable waste management system, Korea went through many regulatory improvements and discoveries, which are presented below [23-27].

In 1995, a volume-based waste disposal system was introduced, which is a waste containment system that uses the principle of payment for emissions. This system, which is representative of market incentives in Korea, represents a shift from the old system in which a fixed fee was charged regardless of the volume of waste disposed, to a system in which a proportional charge is applied to the volume discharged. As reported, this provides an incentive to reduce discharge and increase processing. In addition, a Promotion of Installation of Waste Facilities and Assistance Law was issued in 1995 to related areas in order to prevent the NIMBY phenomenon (not in my backyard) due to the installation of incinerators, and also to help resolve social conflicts through means such as relief projects for affected communities [28].

In the 2000s, the foundation was created for a society of resource recycling. According to this master plan, the waste was not just recycled, but recycled as a resource. Korea is currently pursuing a "Zero Waste" policy that seeks to use waste as a source of resource, in addition to minimizing waste generation, which was emphasized by the authors of [29].

Since the late 2000s, a reduction in greenhouse gases has been necessary due to the rapid increase in prices for resources and energy, as well as global warming. Therefore, the government emphasized the need to restore resources and energy from waste. In September 2011, the Korean Ministry of the Environment developed the First Framework Plan (2011-2015) for the management of resources, to form the basis for waste management and thereby promote green growth aimed to at encouraging the effective societal dealing with resources (without waste) [30]. In addition, the measure to facilitate the transition to a resource circulation society (2013) facilitates the collection and transportation of recyclable resources through the free collection of large household electronic waste, the consolidation of the sorting system, and the expansion of equipment installation. Waste energy utilization facilities and other similar complexes are the foundations of a waste recycling society [31]. The creation of a market for processed products and support for their industries was also announced.

Currently, intensive advertising and educational programs are beginning to educate the population on how to classify recyclables and use designated garbage bags, and, more importantly, to educate the public on the purpose and significance of waste reduction [31-33]. Due to difficulties in monitoring the levels of flies in rural areas, residents are not required to take out the trash in specially designed trash bags. Instead, public trash and recycle bins were installed in rural areas, and the fees are shared among all residents of the community. Local officials noted that low-income people were offered appropriate assistance to alleviate the burden of paying for MSW. It is interesting to compare waste quantities in different Asian countries; many of these countries employ similar approaches to waste treatment (Table 2).

The Framework Act on Resource Circulation (FARC) was adopted in 2016 to form the basis for implementing this policy; the Korean government has been applying it since 2018 [33]. The country intends to transform the economic structure, focused on mass production and mass waste, into a much more stable and efficient, resource-oriented structure at a fundamental level. The provisions of this framework can be divided into three categories, each of which creates a framework for the circulation of resources, stimulates the circulation of resources and supports the processing industry. It introduces new waste management related programs such as the Recyclable Resource Recognition Program (RRRP), Resource Circulation Performance Management Program (RCPMP), Waste Disposal Tariffs, etc. [33,34]. The government expects to obtain economic, environmental and social benefits 
by preventing environmental pollution, but is also aware of the fact that the country needs to make further efforts to change the paradigm of its waste management policy.

Table 2. Comparison of waste quantities among countries of Asia.

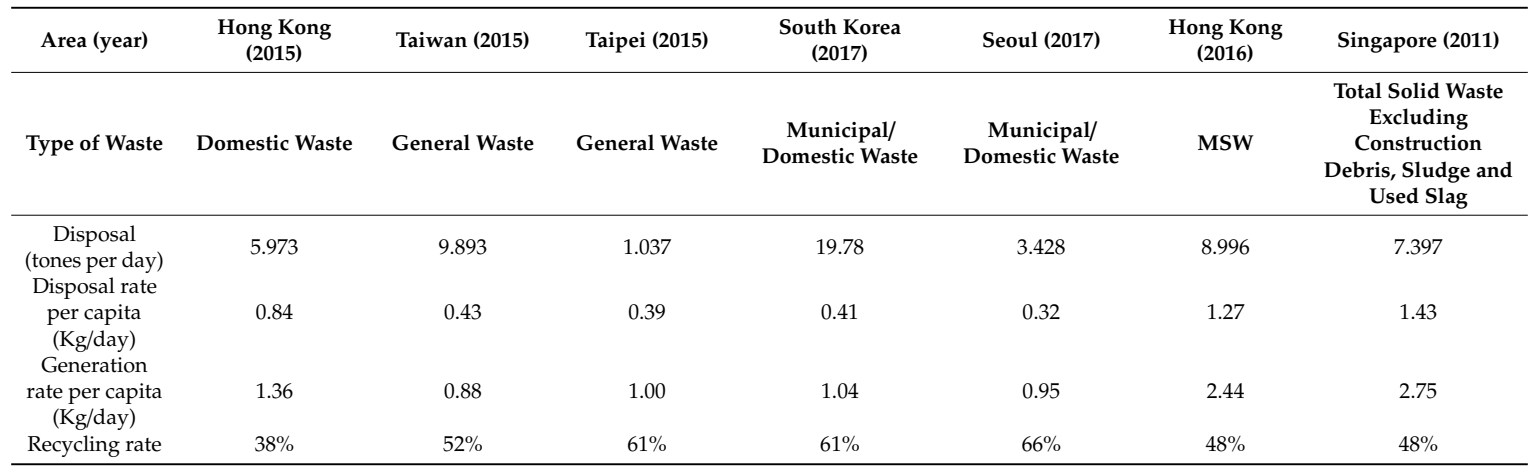

Source: Environmental Protection Department of Hong Kong; Environmental protection authority of Taiwan; Ministry of Environment of South Korea; National Environment Agency of Singapore [32].

\subsection{Waste Management System in Samsung Electronics Corporation}

To protect the environment in times of crisis and make more efficient use of resources, Samsung Electronics is working to focus on a circular economy. Going beyond the normal practice of single-use resources and throwing them away, the Samsung Corporation is working to ensure that resources are reused through recovery, reuse, and disposal at the end of the product's life. By minimizing the type of materials used and optimizing the assembly method, the company has developed production methods that minimize the use of resources [35]. By collecting products that have expired, they acquire valuable materials. Through this circular economy, the Samsung Corporation is reducing the amount of natural resources it requires, reducing greenhouse gas and pollutant emissions from waste incineration, and preventing soil and groundwater pollution from landfills.

Samsung responsibly has to collect and recycle old, unwanted or nonworking electronic products in the U.S.; therefore, the company has to develop new and adaptive programs to manage the recycling needs of its business partners. This is not always easy to manage- - but the reasons behind it are twofold:

- Firstly, to provide a stable service for customers (no matter where they are located in the U.S.), so there is the task of using such a project to provide an easy way for customers to responsibly recycle their products.

- Secondly, to abide by the Samsung Corporation's commitment to responsible recycling.

- The problem is that all these projects require critical analysis, risk-management efforts and cost-analysis. Unfortunately, these were not initially conducted, and the company now has severe restrictions to its waste-management strategies.

The best way to conserve resources is to make quality, durable products. The Samsung Corporation extends the life of products by making an additional contribution to the circular economy and resources by increasing the longevity of its products prior to release, carrying out a series of rigorous reliability tests, and providing convenient repair services through their global service centers, including ongoing software updates.

The amount of waste generated during the product development and manufacturing processes is significant. For complex electronic devices with numerous components, even the packaging is thrown away for every part. At the end of the project, many of the pilot products, which are used to improve the product, are lost. If all of them are burned or buried, the environment will be polluted and resources depleted. By processing waste through an environmentally responsible recycling company, the Samsung Corporation has increased the amount of recyclable materials it utilizes, and achieved its overall waste recycling goal of 95\% in 2016-four years earlier than was planned (Figure 2). 


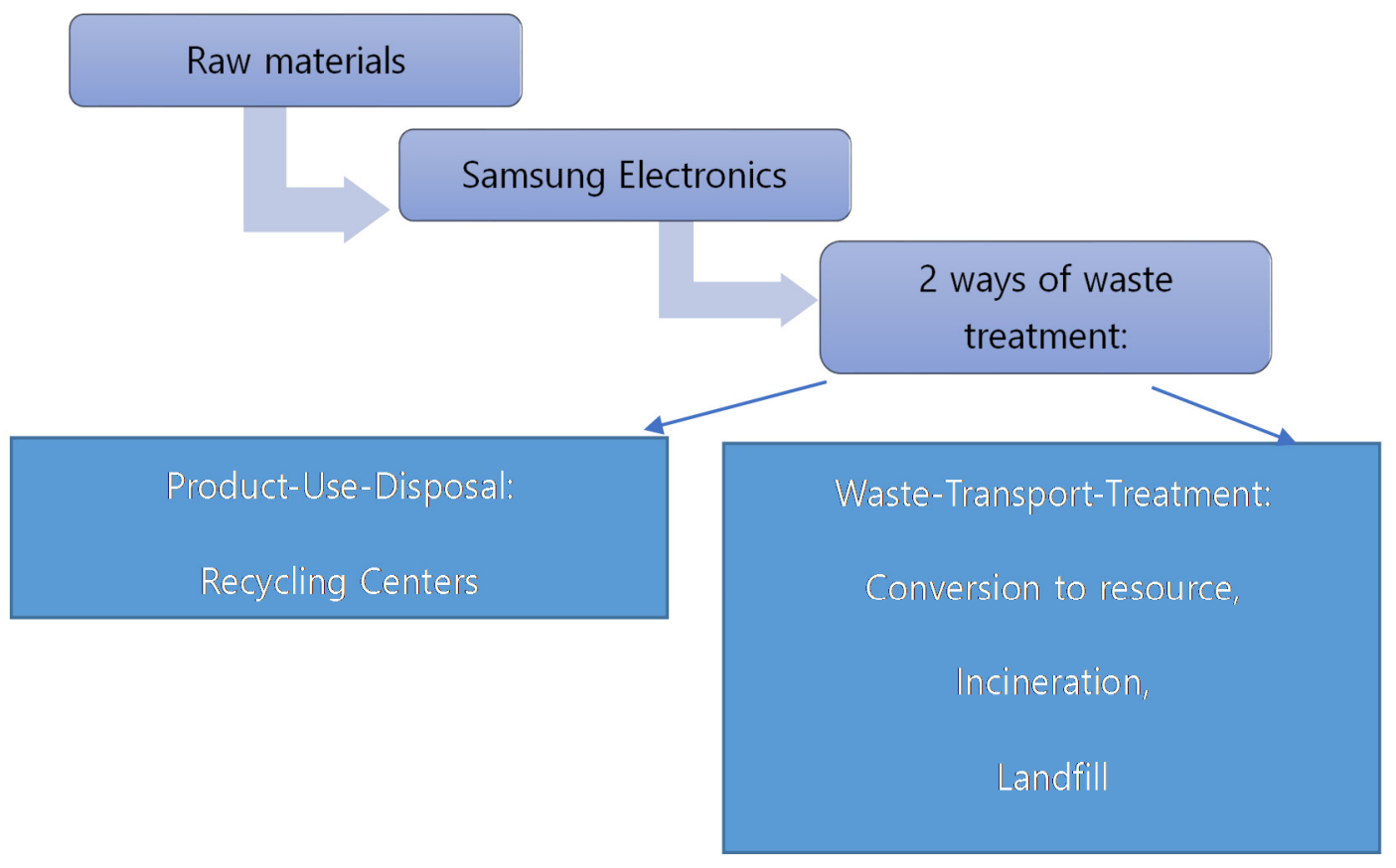

Figure 2. Waste treatment process in Samsung Electronics [36].

Since 2016, Samsung Electronics has been continuously implementing the Galaxy Upcycling Project, which turns old Galaxy smartphones that are no longer in use into new IoT devices. Using such IoT devices, for example, pet feeders and doorbells, etc., the company was able to improve the quality of life of its consumers and, at the same time, protect the environment.

In 2018, the company completed a project to develop a low-level ophthalmoscope using Galaxy Upcycling technology as an appropriate technology [36]. In collaboration with the Yonsei University Health System Design Specification-which Samsung Electronics supports as part of Tomorrow's Decision Program (based on competition events)—ophthalmoscopes have been developed that can be used in developing countries where people cannot receive proper medical treatment because of the difficulty in distributing expensive diagnostic devices. As a result, many people in developing countries are expected to develop blindness. In addition, the company has a plan to expand the use of technology for cervical diagnostic devices-among other things-and promote better health in developing countries. The Galaxy Upcycling plans offer a variety of concepts that go beyond the health sector to reduce resource waste in collaboration with institutions that seek to achieve sustainable development with limited resources.

So, the Samsung Corporation has put forward many proposals to invest in the Korean system of waste management. However, these proposals should have business planning directions and risk-management support. Even if Samsung Engineering offers a full range of EPC services for a variety of industries, from hydrocarbon offshore facilities to wastewater treatment, from initial financing through operation and management, many consulting companies will try to develop an effective financial and risk-preventive model for it. EPC stands for "Engineering, Procurement, Construction", and is a prominent form of contracting agreement in the construction industry. In this case, we want to present the waste treatment investment project's evaluation approach.

\section{Methods}

All national and foreign enterprises in Korea, to one degree or another, are engaged in investment activities in waste processing; in addition, the decision-making associated with such investment in waste processing involves various complex factors, including limited financial resources, the type of investment, and the possible losses that an enterprise may suffer if the project subsequently turns out to 
be less profitable or if it fails completely for unforeseen circumstances [37-40]. Thus, risk management allows us to confirm the viability of decisions for the project and reduce the likelihood of adopting an ineffective or unprofitable project.

In light of the discussions held so far, we consider the following research questions (RQ) in our study:

RQ1: What is the relevance of investment projects in South Korea for reducing the environmental impact of industrial production?

RQ2: What are the positive effects and shortcuts of the application of multi-criteria approaches for the evaluation of waste processing investment projects with uncertainty consideration?

RQ3: What are the risks and disadvantages of multi-criteria approaches for the assessment of waste treatment investment projects?

The remainder of this paper is organized as follows: The current trend of waste management in South Korea is discussed in Introduction Section 1. Environmental policies and waste management methods are discussed in Section 2. Section 3 describes the method, within which we consider the analysis of the feasibility and management an optimal investment project in a risk environment based on the Pareto model. Section 4 presents the results and discussion, which present various possible calculations within the framework of the discussed model. These calculations prove various possible situations for applying this method, as well as the possibility of using other performance indicators with our method. In addition, various approbations of this method in future research projects are discussed. In conclusion, Section 5 presents the main results of testing the methodology for evaluating investment projects in the field of waste management, describes our findings and predicts possible future discussions in this area.

In this research, we continuously develop this approach and take into account the risk of multivariate estimation. Vedernikov and Mogilenko in 2011 [41] suggest that uncertainty has a number of factors that affect the results of actions. Actions in this case cannot be clearly defined, and questions about how to determine the degree of possible influence of these factors on the results are accumulated. Therefore, when determining methods for industrial waste management, and methods of investing in the development of processing technologies are considered, it is important to identify the possible risks and damages from the effects of poorly predicted external factors in detail. In doing this, it is possible to carry out a scenario analysis of market risks, as well as assess the possible effects of new approaches in industrial waste management systems. This approach allows us to take the assessment of the aggregated scenario of factors into account, which enables us to represent various types of risks as components of the analysis [42-45]. This is shown in Figure 3.

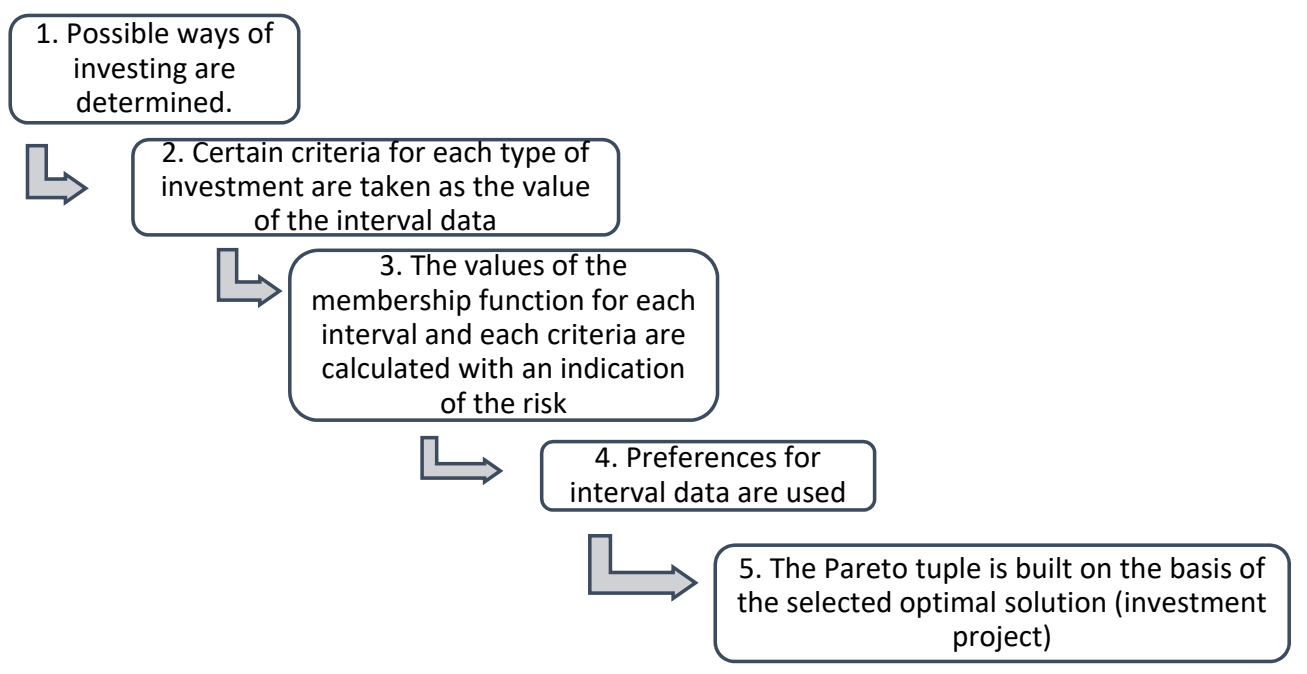

Figure 3. Research methodology. 
In 2013-2017, Rodionova et al. began to analyze an integrated approach to making investment decisions, including the calculation of NPV, DPP and IRR for each alternative [42-44]. In addition, this approach is specific, since it takes the uncertainty of the external environment into account [45-48]. For this, expert assessments of the probability of damage from the implementation of the project and the intervals of fluctuations of the three criteria are used to assess the effectiveness of the investment project.

IRR measures the effectiveness of capital investments; thus, this indicator partially allows a comparison between investment projects with different capital investments and terms of implementation. The typical methodological recommendations for calculating the effectiveness of investment projects solve the problem of selecting from alternative projects by using the NPV indicator for risk evaluation. This method is useful for certain cases, such as efficiency comparison within existing external circumstances. This recommendation helps avoid conflict of interests in terms of which indicators to use. We suggest to include them all, as they each reflect different aspects (e.g., uncertainty, market situation, project capacity, etc.) of the economic system. Each of these aspects is important for the formation of criteria in the economic system.

There are four primary reasons that justify the use of multicriterial (MCA) methods; these are listed as follows:

(i) MCA methods allow the investigation and integration of the interests and objectives of multiple actors, because both quantitative and qualitative information from every actor is considered in forming the criteria and weight factors.

(ii) These methods address the complexity of a multi-actor setting by providing output information.

(iii) These are well-known and commonly used methods for the assessment of investment alternatives. Moreover, different versions of these methods are developed for specific contexts.

(iv) MCA methods allow for the objectivity and inclusiveness of the different perceptions and interests of actors.

Because Cost Benefit Analysis (CBA) is dependent on the time at which it is being performed, it is more appropriate as an ex-ante instrument; in contrast, the multi-criteria approach can be adopted for both ex-ante and ex-post assessments, which is an advantage of the MCA. Considering the dimensions of the project or the policy to be evaluated, the characteristics (evaluative standpoint, decision-relevance, comparability, verifiability, accountability, and scientific progression) of CBA and MCA render the dimensions of the project useful. In particular, on a large scale-i.e., when public and private costs are consistent-the CBA approach is necessary, whereas MCA appears to be useful on a small-scale, where all the stakeholders can be considered individually and can be consulted or express informed opinions on their priorities.

Based on the discussion thus far, it is necessary to use methods for the evaluation of the effectiveness of alternative investment projects that are based on multi-criteria selection. However, the known methods for multi-criteria selection are still not considered in the commonly used methods that can solve the problem of selecting the optimal investment solution (Roy, 1976). In particular, the selection of an effective investment project involves the best combination of values based on the analysis of disparate indicators characterizing the investment project.

We assess the variety of values for all components of the model, taking into account the risk associated with alternative waste treatment investment projects. Intervals are determined by both the absolute values of indicators and by estimates [49-52].

To evaluate the effectiveness of alternatives and to select the most preferable, our method is based on the built-in interval preference ratio (IPR).

Let us suggest that $I=\left\{I_{\alpha}, \alpha=1 \ldots n\right\}$ is a pool of types of waste treatment investment projects; $K_{i}\left(I_{\alpha}\right)=\left[A_{i}\left(I_{\alpha}\right) ; B_{i}\left(I_{\alpha}\right)\right]$ represents the standards for assessing the effectiveness of every investment project within the interval type; $i=1 \ldots r, r$ is the total range of evaluation criteria; $A_{i}\left(I_{\alpha}\right)$ and $B_{i}\left(I_{\alpha}\right)$ are the area units of the lower and higher bounds of the interval analysis; $K\left(I_{\alpha}\right)=\left\{K_{1}\left(I_{\alpha}\right), K_{2}\left(I_{\alpha}\right), \ldots\right.$ $\left.K_{r}\left(I_{\alpha}\right)\right\}=\left\{\left[A_{1}\left(I_{\alpha}\right) ; B_{1}\left(I_{\alpha}\right)\right]\right.$, and $\left.\left[A_{2}\left(I_{\alpha}\right) ; B_{2}\left(I_{\alpha}\right)\right], \ldots\left[A_{r}\left(I_{\alpha}\right) ; B_{r}\left(I_{\alpha}\right)\right]\right\}$ are the direction indicators of every 
waste treatment investment project's effective results. We tend to introduce the notation II for the set of Pareto-optimal information processing $I P(I I \subset I)$, with the amount of parts $\gamma \leq n$ meeting the main condition $I I_{m 1}>I I_{m 2}>\ldots I I_{m y}, m_{j}=1 \ldots y$. Then, the matter may be developed as follows to construct the economic expert tuple of thought of the variants of waste treatment investment flows, the parts of which satisfy one in all the conditions: $K_{i}\left(I_{y j}\right)=\min \left[K_{i}\left(I_{\alpha}\right)\right], I_{y j} \in I I$ or $K_{i}\left(I_{y j}\right)=\max \left[K_{i}\left(I_{\alpha}\right)\right], I_{y j} \in I I$.

We also consider that if the exponent is a scalar amount, it may be mentioned as a degenerate interval with coincident ends $A_{i}\left(I_{\alpha}\right)=B_{i}\left(I_{\alpha}\right)$. This concept was presented by Orlovsky in 1981, Serguieva and Olson in 2014, and Stoyanova in 2006 [53-56].

There is an ambiguity in the choice of standards and the form of factors that the unit considers, due to the quality of the question of assessing the effectiveness of waste treatment investments. It must be assumed that the person responsible for making decisions (usually the project manager) does not have a transparent opinion about the preferences of the analyzed variants. Within the scope of the indicators of victimization, the values of the intervals and the qualitative difference of the measured values-which are expressed in the fact that the difference in the units of assessment-are built, it is convenient to check the options supported by the IPR. This concept was presented by Minakova L. V. and Anikanov P. V. in 2013 [57].

Let $m_{i}$ be the breadth of the estimates' interval for the $i$-th criterion. Consistent with fuzzy methods - which were discussed by Parrino et al. in 2014, Roy in 1976, and Saaty in 1990—-the interval relation of preference $R^{\text {и }}$ on the set $I_{\alpha}$ is the set of the Cartesian product $I_{k} \times I_{l},(k=1, \ldots n, l=1, \ldots n$, $k \neq l$ ) [58-60]. For the characteristic of the set of the Cartesian product, we should take the interval membership operation $\mu^{\mathrm{u}} K_{i}\left(I_{k}, I_{l}\right): I_{k} \times I_{l} \rightarrow[-1 ; 1]$ into account.

$$
\mu^{i} K_{i}\left(I_{k}, I_{l}\right)=m_{i}^{-1}\left(K_{i}\left(I_{k}\right)-K_{i}\left(I_{l}\right)\right)
$$

Each valuable measure of the membership function $\mu^{\mathrm{u}} K_{i}\left(I_{k}, I_{l}\right)$ estimates the degree of injury and gain in recognizing position of $I_{k}$ as the dominant variant $I_{l}$ supported by the criteria $K_{i}$.

The degree of privilege of the choice $I_{k}$ over the choice $I_{l}$, supported by the interval criterion $K_{i}$, is diagrammatically presented by the membership function $\mu_{D}{ }^{\mathrm{u}} K_{i}\left(I_{k}, P_{I}\right)$, which determines the quantitative relation of the strict interval preference.

$$
\mu_{D}^{u} K_{i}\left(I_{k}, I_{l}\right)=\mu_{u} K_{i}\left(I_{k}, I_{l}\right)-\mu_{u} K_{i}\left(I_{l}, I_{k}\right)
$$

For comparison, it is vital to establish that the alternative $I_{k}$ is not undermined compared with the $I_{l}$ alternative, which would be a mistreatment of the membership operation.

$$
\mu_{N D} K_{i}\left(I_{k}, I_{l}\right)=1-x, x \geq 0 ; x=\mu_{D}^{u}\left(K_{i}\left(I_{K}, I_{l}\right)\right.
$$

In this case, for the criterion of the $i$-th interval criteria, the approximation of the alternative $I_{k}$ to the Pareto optimal variant is determined by the index of the membership function for the set of non-privileged alternatives $[61,62]$.

$$
\mu_{D}^{*} K_{i}\left(I_{k}\right)=\min \mu_{N D} K_{i}\left(I_{k}, I_{l}\right)
$$

Wang et al. in 2009, and Zare et al. in 2016 [63,64] suggested that the indicator NPV is based on the quantity of cash flows at a certain time and the discount rate $r$ :

$$
N P V=C_{1}(1+r)^{-t 1}+\ldots+C_{n}(1+r)^{-t n}
$$

The discount rate usually uses the risk-free interest rate or interest rate for investment projects with a similar degree of risk, as well as the market and industry coefficient of efficiency for capital investments. This criterion underlies the choice of an environmental management project with a maximum value, or with the same value of $r$. It is known that NPV is entirely dependent on the 
discount rate; therefore, a poor-quality and unverified forecast of the discount rate definitely leads to risky management decisions. For example, a good project with high-quality technologies, but with high costs, can be rejected, and a project with lower costs but low-quality technologies can be accepted for discussion and subsequent implementation. The refinement of the values of the NPV interval allows us to determine that the maximum possible determining factor for the NPV criterion is the maximum value.

In addition, DPP is represented as a time interval; the optimal condition for this criterion should correspond to its minimum value. Furthermore, IRR is presented as a percentage and is defined as the value of the interval; in accordance with this criterion, the waste treatment investment project that matches the maximum value is selected.

\section{Results}

Risk assessment is predicated on the interval values in the estimates. The presumption is that the rate of interest $\mathrm{r}$ may be a variable, and for that the likelihood of a random event may be found, $N P V(r, t)>0, P(N P V(r, t)>0)=P(r<I R R)=F(I R R)$. Here, $F(x)=P(r<x)$ is the distribution operation of $r$; IRR is the internal rate of pay back, that is obtained as an answer of the equation $N P V(t, r)=0$. For various $r$, it is possible to ascertain the likelihood that the waste treatment project will not pay off at time $t$; then the estimates of victimization are obtained in the analysis procedure. Here, we tend to conduct a risk assessment for the project supported by the explained methodology for three doable and inevitable market conditions; those conditions are then evaluated by consultants, and an evaluation of the probability of every of them is enforced. It ought to be noted that the chance assessment criterion for a waste processing investment project needs to select the most effective possibility, supported by the minimum worth of the standards.

Given the well-known theoretical ideas, the values of $m_{i}$ are selected as the most allowable values for the considered option (standard). The initial knowledge necessary for the calculations and investment analysis are presented in Table 3. Three different investment projects are presented $\left(I_{1}\right.$-investment in landfill production; $I_{2}$-investment in industrial waste recycling R\&D; $I_{3}$-investment in the implementation of green technologies).

Table 3. Data implication for different projects.

\begin{tabular}{ccccc}
\hline Projects/Indicators & $\boldsymbol{I}_{\mathbf{1}}$ & $\boldsymbol{I}_{\mathbf{2}}$ & $\mathbf{I}_{\mathbf{3}}$ & $\boldsymbol{m}_{\boldsymbol{i}}$ \\
\hline$K_{1}(I \alpha)-N P V(\mathrm{USD})$ & {$[50 ; 60]$} & {$[70 ; 120]$} & {$[80 ; 100]$} & 200 \\
$K_{2}(I \alpha)-D P P($ annual $)$ & {$[3 ; 8]$} & {$[4 ; 6]$} & {$[5 ; 9]$} & 10 \\
$K_{3}(I \alpha)-I R R(\%)$ & {$[16 ; 17]$} & {$[10 ; 20]$} & {$[14 ; 18]$} & 30 \\
$K_{4}(I \alpha)$-risk evaluation & {$[6 ; 8]$} & {$[3 ; 9]$} & {$[5 ; 9]$} & 10 \\
$\begin{array}{c}\text { (points) - pessimistic forecast } \\
K_{5}(I \alpha) \text {-risk evaluation } \\
(\text { points)-realistic forecast } \\
K_{6}(I \alpha) \text {-risk evaluation }\end{array}$ & {$[4.5 ; 7]$} & {$[5 ; 8.5]$} & {$[4 ; 7]$} & 10 \\
(points)-optimistic forecast & {$[4 ; 5]$} & {$[4 ; 6]$} & {$[3 ; 5.5]$} & 10 \\
\hline
\end{tabular}

The risk evaluation process is presented using interval values in grade system. Assuming that the rate of interest $r$ could be a variable quantity for which the chance of a random event is found, $N P V(r, t)>0, P(N P V(r, t)>0)=P(r<I R R)=F(I R R)$. Here, $F(x)=P(r<x)$ is the disseminative operation of $r$ IRR is the internal rate of pay back, which is suggested as an explanation of the formula $N P V(t, r)=0$. For variety of $r$, it is important to determine the likelihood that the investment project will not be profitable at time $t$. Then the results will be determined through the evaluation analysis procedure. This study assesses the risk of an industrial waste management project using the aforementioned methodology for three defined and predicted market conditions, and an expert assessment of the likelihood of each of market condition is introduced. It is important to indicate that 
the risk assessment criterion for a waste processing investment project requires the selection of the best option based on the minimum value of the criteria.

Based on known theoretical models, $m_{i}$ values are defined as the maximum allowable indicators for the criteria under consideration. The initial data necessary for calculations on the analysis of investment projects are presented in Table 3.

Taking in consideration Equation (1), we achieve the appraisal of the membership operation $\mu^{\mathrm{u}} K_{i}\left(I_{k}, I_{l}\right)$ for each pair of variants for each criterion and calculate their estimated matrices. Thus, Equation (1) can be expanded as:

$\mu^{u} K_{i}\left(I_{k}, I_{l}\right)=\left(\left[\min \left\{A_{i}\left(I_{k}\right)-A_{i}\left(I_{l}\right) ; B_{i}\left(I_{k}\right)-B_{i}\left(I_{l}\right)\right\} ;\right.\right.$

$\left.\left.\max \left\{A_{i}\left(I_{k}\right)-A_{i}\left(I_{l}\right) ; B_{i}\left(I_{k}\right)-B_{i}\left(I_{l}\right)\right\}\right]\right) / m_{i}$

and be denoted by

$C_{i}^{k l}=\min \left\{A_{i}\left(I_{k}\right)-A_{i}\left(I_{l}\right) ; B_{i}\left(I_{k}\right)-B_{i}\left(I_{l}\right)\right\} / m_{i}$,

$D_{i}^{k l}=\max \left\{A_{i}\left(I_{k}\right)-A_{i}\left(I_{l}\right) ; B_{i}\left(I_{k}\right)-B_{i}\left(I_{l}\right)\right\} / m_{i}$

Then,

$$
\mu^{i} K_{i}\left(I_{k}, I_{l}\right)=\left[C_{i}^{k l} ; D^{k l}{ }_{i}\right]
$$

Furthermore, the interval membership function for the $I_{l}, I_{k}$ takes the following form:

$$
\mu^{u} K_{i}\left(I_{k}, I_{l}\right)=\left[-D_{i}^{k l} ;-C_{i}^{k l}\right]
$$

Hence, if the relation $\left|C^{k l}{ }_{i}\right|=D^{k l}{ }_{i}$ is true, then the values $\mu^{\text {u }} K_{i}\left(I_{l}, I_{k}\right) \mu^{\text {un }} K_{i}\left(I_{k}, I_{l}\right)$ coincide.

Based on Equation (2), we take into account the preference frequency for each pair of options for each indicator using the value of the membership operation $\mu_{D}{ }^{\mathrm{h}} K_{i}\left(I_{k}, I_{l}\right)$, and place them in the evaluation matrices. Using Equations (6) and (7), we move the calculations into a simple method.

Thus, we evidently have

$$
M_{D}{ }^{u} K_{i}\left(I_{k}, I_{l}\right)=\left[C_{i}^{k l} ; D_{i}^{k l}\right]-\left[-D_{i}^{k l} ;-C_{i}^{k l}\right]=\left[C_{i}^{k l}+D_{i}^{k l} ; C_{i}^{k l}+D_{i}^{k l}\right]
$$

Thus,

$\mu D^{u} K_{1}(I \alpha)=$

\begin{tabular}{|c|c|c|}
\hline \multicolumn{3}{|l|}{$\mu^{D_{u} K_{4}(I \alpha)=}$} \\
\hline - & 0.2 & 0 \\
\hline-0.2 & - & -0.2 \\
\hline 0 & 0.2 & - \\
\hline \multicolumn{3}{|l|}{$\mu^{D_{u} K_{5}(I \alpha)=}$} \\
\hline- & -0.2 & 0.05 \\
\hline 0.2 & - & 0.25 \\
\hline-0.05 & -0.25 & - \\
\hline \multicolumn{3}{|l|}{$\mu^{D_{u} K_{6}}(I \alpha)=$} \\
\hline- & -0.1 & 0.05 \\
\hline 0.1 & - & 0.25 \\
\hline-0.05 & -0.25 & - \\
\hline
\end{tabular}

\begin{tabular}{rll|}
$\mu_{u}^{D_{u} K_{2}(I \alpha)=}$ & & \\
\hline- & $-\mathbf{0 . 1}$ & $\mathbf{- 0 . 3}$ \\
\hline-0.1 & - & -0.4 \\
0.3 & 0.4 & - \\
\hline
\end{tabular}

\begin{tabular}{l|cc|}
$\mu^{D_{u}} K_{3}(I \alpha)=$ \\
\hline- & 0.1 & $\mathbf{0 . 0 3}$ \\
\hline-0.1 & - & -0.06 \\
-0.03 & -0.06 & - \\
\hline
\end{tabular}

From Equations (3) and (4), we achieve the valuable measures of the membership function $\mu_{N D}{ }^{\text {I }} K_{i}\left(I_{k}, I_{l}\right)$ for each pair of options for each criterion, and assemble the membership function valuable measures for the set of non-privilege options $\mu_{D} K_{i}\left(I_{k}\right)$ :

$\mu_{D}^{*} K_{1}\left(I_{k}\right)=\{0.6,1,0.95\} ;$

$\mu_{D}{ }^{*} K_{2}\left(I_{k}\right)=\{0.9,1,0.6\}$; 
$\mu_{D}^{*} K_{3}\left(I_{k}\right)=\{1,0.9,0.93\} ;$

$\mu_{D}^{*} K_{4}\left(I_{k}\right)=\{1,0.8,1\} ;$

$\mu_{D}^{*} K_{5}\left(I_{k}\right)=\{0.9,0.75,1\} ;$

$\mu_{D}{ }^{*} K_{6}\left(I_{k}\right)=\{0.95,0.75,1\}$.

After analyzing the values of $\mu_{D}{ }^{*} K_{i}\left(I_{k}\right)$, we can conclude that the investment project $I_{2}$ is the best option based on the criteria $K_{1}\left(I_{\alpha}\right)$ and $K_{2}\left(I_{\alpha}\right)$, the investment project $I_{1}$ is the best option based on the criteria $K_{3}\left(I_{\alpha}\right)$ while it is possible to perform risk management in a pessimistic scenario of market development, and investment project $I_{3}$ is optimal in terms of risk, based on the considered set of options for waste processing investment projects [65-67].

Savchuk in 2007, and Syroezhin in $1980[68,69]$ suggested that in order to determine the best preference in this set of waste management investment projects, it is necessary to determine the vector preference using some previous studies in this area (membership functions $\mu_{D}{ }^{*} K_{i}\left(I_{k}\right)$ determine the degree of proximity of variant $I_{k}$ to the Pareto-optimal variant of an investment project using the $K_{i}$ criterion; this justifies the use of special criteria instead of traditional factors, indicating the importance of the indicator. The next step is to compare the variants $I_{k}$ and $I_{l}$ in pairs, calculate the values of $\mu_{D}{ }^{*} K_{i}\left(I_{k}\right)$, and introduce the subsets $I_{k l}{ }^{+}, I_{k l}{ }^{-}$, and $I_{k l}{ }{ }$ for optimal, pessimistic and realistic values of $\mu_{D}{ }^{*} K_{i}\left(I_{k}\right)$ and $\mu_{D}{ }^{*} K_{i}\left(I_{k}\right)$, (where $i=1 \ldots 4 ; k, l=1, \ldots 3, k \neq l$ ) of these variants, respectively. The next step determines the elements of the estimation matrix $\mathbf{C}=\left\|C_{k l}^{\mu}\right\|$ based on these conditions; this is shown in Table 4.

$$
C_{k l}^{\mu}=\left(\sum_{i=1}^{3} \mu_{D}^{*} K_{i}\left(I_{k}\right)\right)\left(\sum_{i=1}^{3} \mu_{D}^{*} K_{i}\left(I_{l}\right)\right)^{-1}
$$

Table 4. Evaluation matrix.

\begin{tabular}{cccccc}
\hline$I_{k l}^{+}$ & $\boldsymbol{I}_{\boldsymbol{k} \boldsymbol{l}}^{-}$ & $\boldsymbol{I}_{\boldsymbol{k} \boldsymbol{l}}^{=}$ & $C_{k l}^{\mu}$ & $C_{l k}^{\mu}$ & Notes \\
\hline$\varnothing$ & $\varnothing$ & $\{1 . .3\}$ & 1 & 1 & - \\
$\{1 . .3\}$ & $\varnothing$ & $\varnothing$ & $N_{2}$ & 0 & - \\
$\varnothing$ & $\{1 . .3\}$ & $\varnothing$ & 0 & $N_{2}$ & - \\
$\neq$. & $\varnothing$ & $\neq 0$ & $N_{3}$ & 0 & $1<<N_{3}<N_{2}$ \\
$\varnothing$ & $\neq<$ & $\neq 0$ & 0 & $N_{3}$ & - \\
$\neq<$ & $\neq<$ & $\left|S_{k l}^{=}\right| \geq 0$ & Formula (8) $\quad C_{l k}^{\mu}=1 / C_{k l}^{\mu}$ & - \\
\hline \multicolumn{5}{c}{ Source: Prisyach E., 2018 [70]. }
\end{tabular}

The matrix is created considering the risk criteria; therefore, it is necessary to pay attention to the possibility of various risk conditions being weighted evaluated options of the matrix component.

$C_{k l}{ }^{\mu}=\left(\sum^{*}{ }_{i=1} a_{i} \mu_{D}{ }^{*} k_{i}\left(I_{k}\right)\right)\left(\sum^{*}{ }_{i=1} a_{i} \mu_{D}{ }^{*} k_{i}\left(I_{i}\right)\right)^{-1}$,

$\left\{\begin{array}{l}a_{i}=1, i=1,2,3 \\ p_{i}, l=4,5,6\end{array}\right\}$

Then, we get the following matrix of preferences

$\mathbf{C}=$\begin{tabular}{|ccc|}
\hline- & $\mathbf{0 . 6 6}$ & $\mathbf{5 . 0 1}$ \\
\hline 1.51 & - & 0.94 \\
0.19 & 1.05 & - \\
\hline
\end{tabular}

Using well-known theoretical methods and developing a methodology for evaluating investment projects, we introduce the indicators $G^{\mu}{ }_{l}$ and $H^{\mu}{ }_{l}$, which denote the set of elements of the $l$-th column in $C$, the value of which is less than one, but greater than zero and more than one, respectively, and the exponent $C^{\mu}{ }_{k l \text { max }}$, which is equal to the indicator of the maximum value of the $l$-th column. It can be argued that $H^{\mu}{ }_{l}$ represents the number of investment project options that dominate the $l$-th column. Furthermore, $G^{\mu} l$ shows the number of investment project options that dominate the $l$-th column, 
and $C^{\mu}{ }_{k l \text { max }}$ represents the maximum level of dominance of the $k$-th version of the investment project over the $l$-th column.

We include these indicators in the matrix, as shown in Table 5.

Table 5. Matrix of variations.

\begin{tabular}{cccc}
\hline Investment Projects, Variants Indicators & $\mathbf{I}_{\mathbf{1}}$ & $\mathbf{I}_{\mathbf{2}}$ & $\boldsymbol{I}_{\mathbf{3}}$ \\
\hline$G_{l}^{\mu}$ & 1 & 1 & 1 \\
$H_{l}^{\mu}$ & 1 & 1 & 1 \\
$C_{k l \text { max }}^{\mu}$ & 1.51 & 1.05 & 5.01 \\
\hline Source: made by authors. & & &
\end{tabular}

According to the results of Table 5 , investment project $I_{2}$ turned out to be the best variable alternative with a minimum value of $C^{\mu}{ }_{k l}$ max. In this regard, the second version of investment design should be included in the Pareto tuple, but is excluded from the subsequent analysis. For this exception procedure, we delete the corresponding row and column in the preference matrix.

At the next stage, we analyze the other (above mentioned) options for investment design, and analyze them using the new matrix of indicators in a similar way.

As a result, the Pareto preference tuple can be denoted as $I I=\left\{I_{2}, I_{1}, I_{3}\right\}$. In this regard, the best alternative for the vector of the heterogeneous performance index is $K(I \alpha)=\{K 1(I \alpha), K 2(I \alpha), K 3(I \alpha)$, $K 4(I \alpha), K 5(I \alpha), K 6(I \alpha)\}$. In the Pareto tuple of the three options considered, those criteria that characterize NPV-discounting for calculating DPP in the vector efficiency index-became preferable.

Based on Table 5, the best alternative to an investment project with a minimum value max is option $I_{2}$. Therefore, the second version of the investment project is included in the Pareto tuple and excluded from further analyses by deleting the corresponding row and the column in the preference matrix.

The remaining options are analyzed using the new matrix of indicators in a similar manner.

Finally, the tuple of Pareto preferences can be obtained as $I I=\left\{I_{2}, I_{1}, I_{3}\right\}$. Therefore, the best alternative for the vector inhomogeneous efficiency index $K\left(I_{\alpha}\right)=\left\{K_{1}\left(I_{\alpha}\right), K_{2}\left(I_{\alpha}\right), K_{3}\left(I_{\alpha}\right), K_{4}\left(I_{\alpha}\right), K_{5}\left(I_{\alpha}\right)\right.$, $K_{6}\left(I_{\alpha}\right)$ \} should be recognized as the second variant. In the Pareto tuple of the considered variants, preference was expressed for the criteria characterizing the NPV and discounting the calculation of the DPP in the vector efficiency index.

So, to answer the research questions which were submitted in Section 3, we consider these research points and describe them above to show the significance of this research:

(i). The proposed methodology for using interval values and assessing the effectiveness of investment projects in the field of industrial waste management gives experts new opportunities for the simpler and more accurate analysis of proposed opinions. In addition, uncertainties can be considered without additional statistic indicators.

(ii). This allows managers to evaluate various criteria in different environmental conditions and the influence of factors; furthermore, it allows reflecting on various aspects of the measured phenomena (in particular, the effectiveness of the waste processing investment project).

(iii). The proposed set of indicators may include an extended list of influential factors beyond those that are part of the project environment.

\section{Discussion}

Since Korea's volume of waste is evidence of changing lifestyles in the midst of a trend toward a convenience-oriented life (single-use products, convenient goods, instant food, etc.) and an abundant capitalist socioeconomic environment (mass consumption/mass production), the current state of waste management in Korea is at a turning point, where a paradigm shift from a convenience-oriented society (single-use product society) to a society oriented toward resource conservation (resource-circulating society) is taking place [71,72]. Wastes have a close relationship with each country's life and cultural 
patterns, as well as with changes in society, patterns of waste generation and treatment, thereof, change. A summary of the evolution of Korea's system of legislations for waste management shows that this evolution has been taking place alongside the flow of developmental processes in Korea, and each developing country needs to introduce waste policies suitable for its current economic and social conditions. These policies should be supported with investment perspectives and based upon the development of technology and innovation [73-75].

According to the well-developed support policies of waste treatment investment projects and new environmental regulations, the Korean Government expects to observe some effects in terms of the economic, environmental and social impacts of the Framework Act on Resource Circulation (Table 6).

Table 6. Expected results from investment activities in Korean waste management systems.

\begin{tabular}{cll}
\hline Impact & \multicolumn{1}{c}{ Current Situation } & $\begin{array}{c}\text { After Investment and Introduction of } \\
\text { New Regulations and } \\
\text { Technology Performance }\end{array}$ \\
\hline Economic & $\begin{array}{l}\text { Increasing dependence on foreign } \\
\text { resources due to the depletion of natural } \\
\text { resources (97\% of energy, 90\% of } \\
\text { mineral resources are imported). }\end{array}$ & $\begin{array}{l}\text { Increased use of circulated resources } \\
\text { (yearly quantity of recycling increases by } \\
\text { about 10 million tons) } \rightarrow \text { Recycling } \\
\text { market of about 1 trillion and 70 million } \\
\text { won; about 10,000 jobs created. }\end{array}$ \\
\hline Environmental & $\begin{array}{l}\text { Concerns of a trash crisis due to } \\
\text { decreasing capacity of remaining } \\
\text { landfill sites. }\end{array}$ & $\begin{array}{l}\text { Decreased quantity of landfill disposal } \\
\text { due to the levying of landfill disposal and } \\
\text { incineration fees } \rightarrow \text { increased lifespan of } \\
\text { remaining landfill sites. }\end{array}$ \\
\hline Social & $\begin{array}{l}\text { Intensifying opposition of residents in } \\
\text { surrounding areas due to worsening } \\
\text { conditions in areas surrounding } \\
\text { landfill sites. }\end{array}$ & $\begin{array}{l}\text { Improvement of surrounding } \\
\text { environments, support for local residents } \\
\text { co-existence of dischargers and } \\
\text { residents living in areas surrounding } \\
\text { landfill sites. }\end{array}$ \\
\hline
\end{tabular}

Source: adopted by authors from Joint work of related departments and agencies, September 2011, the 1st Framework Plan for Resource Circulation (2011-2015) [76].

Waste treatment investment projects are needed to be classified according to the type of waste treatment and operational technology. Each investment project requires risk analysis, which should be evaluated. For further research, it is necessary to identify the correlation between risk type and used technology in waste treatment operations.

Risk-evaluation procedures are the importing starting points for waste management. A welldesigned risk evaluation system presents a structured mechanism for searching for potential problems and creating judgements on the consequences. Assessing the risks of waste processing investment underpins the "suitable for use" approach adopted by the Korean regulatory mechanism and supports planning policy [77]. The main goal is to decide whether there are any unacceptable risks to people or the wider environment-including industries. The risk evaluation process can be very detailed, particularly where risks are diversified. For the discussion of investment in waste recycling, there are a range of specific technical approaches for different contaminants and circumstances.

However, these all broadly fit within a general process that can be seen as a tiered approach. Each tier is applied to the case circumstances, with an increasing level of detail information required by the assessor in progressing through each tier [78].

There are three tiers, or steps:

1. Basic risk evaluation.

2. Risk assessment using generic criteria and assumptions-where a contamination concentration is compared against a generic Soil Guideline Value (SGV).

3. Risk assessment using specific criteria and assumptions-where a detailed, site-specific approach is used. 
During the management of investment projects in the field of industrial waste management, it is important to determine the possible influence of various external factors on the result (market factors, production factors, technological factors, social factors, etc.). In this case, the degree of occurrence of a particular risk is determined and an initial assessment of risk is carried out. Depending on the likelihood of a negative event in the external environment of the investment project and the degree of negative influence of factors on its successful implementation, managers can use only one approach to assess risks, or conduct a multi-stage risk analysis. Usually it depends on the properties (complexity and degree of influence) of pollutants-some of them can be evaluated using common criteria; others may need to develop specific indicators for a more detailed and comprehensive risk assessment.

\section{Conclusions}

Our proposed investment project selection algorithm discusses the associated risks and allows us to determine the degree of their influence on the result of improving the environmental safety systems of production facilities. Do not forget that this examines the various conditions and components of the economic and environmental systems, as well as identifies all possible risks in each of them. This is achieved by describing risk situations and introducing a multi-component presentation of the risk component as one of the decision criteria. In subsequent studies, it will be necessary to identify a correlation effect between environmental factors and elements of the ecological and economic systems.

The investment project appraisal approach proposed in this study opens up new possibilities for applying the multi-criteria selection method to the conditions of economic and environmental activities in the field of waste management.

For the successful selection and implementation of an investment project in the field of waste management, it is extremely important to carry out the following management activities:

(i) Determine the form of investment policy of the enterprise.

(ii) Develop the structure of the investment project.

(iii) Study the multi-factor impact of local or global economic and environmental environment on the investment project management.

(iv) Calculate the volume of risk conditions and classify all possible risks.

(v) Develop a risk management scenario and process calculations for their management and dissemination.

This paper is a combination of three elements: (i) presentation of the South Korean policy for waste, (ii) case study of the Samsung Corporation waste management system, and (iii) a multidimensional approach to risk-analysis in investment projects. Let us summarize the correlation between these three parts:

(i) Presentation of the South Korean policy for waste-this refers to the different programs and advanced technologies which are presented in Korean waste management practice. The authors show how Korean companies and legal organizations develop systems of waste management.

(ii) The story of the Samsung Corporation is presented in case study format. The authors present some successful examples of waste management decisions by the company, with both risks and open questions, including how to successfully manage waste treatment projects in local and global markets, and how to install advance technologies within a cost-leadership strategy.

(iii) The authors discuss four primary reasons justifying the use of multicriterial (MCA) methods in waste management practice; they are mentioned in Section 3.

Thus, our proposed method allows us to use multidimensional and specific information for the process of making comprehensive economic and environmental (managerial) decisions in a market system. Moreover, our algorithm can be used to make long-term strategic decisions in the field of investment risk management in environmental and economic systems.

Author Contributions: J.H.L. and O.A.S. conceptualized the study; J.H.L. designed the methodology; O.A.S. carried out the investigation; J.H.L. and O.A.S. did the analyses, validation, and data curation; O.A.S. wrote 
the paper, and J.H.L. contributed to reviewing and editing all sections; J.H.L. supervised the work. All authors have read and agreed to the published version of the manuscript.

Funding: This research was done as a part of Research project 2020-0108 and was funded in 2020 by Korea University of Technology and Education (KOREATECH).

Conflicts of Interest: The authors declare no conflict of interest.

\section{References}

1. Knowledge Sharing Program Development Research and Learning Network. Available online: http://www.ksp. go.kr/english/index (accessed on 12 March 2020).

2. Kim, K.; Kim, Y. Volume-based Waste Fee System in Korea; Ministry of Strategy and Financy: Seoul, Korea, 2012; pp. $45-78$.

3. Hou, L. South Korea's Food Waste Solution: You Waste, You Pay. Commonwealth Magazine, 2013. Available online: http://english.cw.com.tw/article.do?action=show\&id=14067 (accessed on 12 March 2020).

4. Bekun, F.V.; Alola, A.A.; Sarkodie, S.A. Toward a sustainable environment: Nexus between CO2 emissions, resource rent, renewable and nonrenewable energy in 16-EU countries. Sci. Total Environ. 2019, 657, 1023-1029. [CrossRef]

5. Shvetsova, O.A. Development of Environmental Management in South Korea: Practice of Industrial Waste Processing. In Proceedings of the 2018 IEEE International Conference in Management of Municipal Waste as an Important Factor of Sustainable Urban Development, WASTE, St. Petersburg, Russia, 4-6 October 2018; pp. 93-97.

6. Paramati, S.R.; Apergis, N.; Ummalla, M. Dynamics of renewable energy consumption and economic activities across the agriculture, industry, and service sectors: Evidence in the perspective of sustainable development. Environ. Sci. Pollut. Res. 2018, 25, 1375-1387. [CrossRef]

7. Kim, K. Performance of Waste Management Policy in Korea; Ministry of Environment: Seoul, Korea, 2008.

8. Waste Management Review. South Korea Legislates Towards a Zero Waste Society. Waste Management Review, 2015. Available online: http://wastemanagementreview.com.au/south-korea-legislates-towards-azero-waste-society/ (accessed on 12 March 2020).

9. Korea's Environmental Review, 2018, Ministry of Environment, ECOREA. Available online: http://eng.me.go.kr (accessed on 12 March 2020).

10. OECD Economic Report 2017. Available online: https://www.oecd-ilibrary.org/economics/oecd-economicsurveys-korea_19990707 (accessed on 12 March 2020).

11. OECD Waste Statistics. 2015. Available online: Data.oecd.org/waste/municipal-waste.htm (accessed on 20 November 2017).

12. Jones, R.; Yoo, B. Korea's Green Growth Strategy: Mitigating Climate Change and Developing New Growth Engines; OECD Economics Department Working Papers, No. 798; OECD Publishing: Paris, France, 2011. [CrossRef]

13. OECD. OECD Economic Surveys: Korea 2018; OECD Publishing: Paris, France, 2018. [CrossRef]

14. Daly, H.E. Some overlaps between the first and second thirty years of ecological economics. Ecol. Econ. 2019, 164, 106-372. [CrossRef]

15. CMG recycling solutions.-[on-line access]. Available online: http://www.thplastics.co.uk/tag/cmg-recyclingsolutions/ (accessed on 12 March 2020).

16. Claborn, K.A.; Brooks, J.S. Can we consume less and gain more? Environmental efficiency of well-being at the individual level. Ecol. Econ. 2019, 156, 110-120. [CrossRef]

17. Freeman, R. A theory on the future of the rebound effect in a resource-constrained world. Front. Energy Res. 2018, 6, 81. [CrossRef]

18. Wackernagel, M.; Hanscom, L.; Lin, D. Making the Sustainable Development Goals consistent with sustainability. Front. Energy Res. 2017, 5, 18. [CrossRef]

19. Hogan, B. Technology Trumps Food Waste in South Korea. Food Waste Focus, 2015. Available online: http://blog.leanpath.com/technology-trumps-food-waste-south-korea (accessed on 12 March 2020).

20. Mancini, M.S.; Galli, A.; Coscieme, L. Exploring ecosystem services assessment through Ecological Footprint accounting. Ecosyst. Serv. 2018, 30, 228-235. [CrossRef]

21. Haasnoot, M.; Kwakkel, J.H.; Walker, W.E.; Ter Maat, J. Dynamic adaptive policy pathways: A method for crafting robust decisions for a deeply uncertain world. Glob Environ. Chang. 2013, 23, 485-498. [CrossRef] 
22. Tonmoy, F.N.; Rissik, D.; Palutikof, J.P. A three-tier risk assessment process for climate change adaptation at a local scale. Clim. Chang. 2019, 153, 539-557. [CrossRef]

23. Ayers, J.; Anderson, S.; Pradhan, S.; Rossing, T. Participatory Monitoring, Evaluation, Reflection and Learning for Community-Based Adaptation: A Manual for Local Practitioners; CARE International: Atlanta, GA, USA, 2012.

24. Research into Modifying/Supplementing Basic Guidelines for Investigations of Preliminary Feasibility (Report); Korea Development Research Institute: Seoul, Korea, 2014; pp. 89-90.

25. GiYoung, R. Zero Waste City, Seoul's New Project; SDI Policy Report No. 61; Seoul Research Institute: Seoul, Korea, 2010; pp. 56-59.

26. Hyun, S. Analysis of the Sorting System under the 'Wastes Control Act'; Legal Research Vol. 41; Korea Legal Research Institute: Seoul, Korea, 2013; pp. 34-45.

27. Transitioning to a Resource Circulating Society, Choices for the Future of Society; Korea Ministry of Environment: Seoul, Korea, 2015; pp. 67-71.

28. Tonmoy, F.N.; El-Zein, A. Vulnerability of Infrastructure to Sea Level Rise: A Combined Outranking and System-Dynamics Approach; European Safety and Reliability (ESREL-2013); CRC Press: Cleveland, OH, USA, 2013; pp. 2407-2414.

29. Pini, B.; River, S.W.; Mckenzie, F.M.H. Factors inhibiting local government engagement in environmental sustainability: Case studies from rural Australia. Aust. Geogr. 2007, 38, 161-175. [CrossRef]

30. JungIm, Y. Methods of Establishing the Foundations of a Zero Waste City; GRI Policy Research No. 63; Gyeonggi Development Research Institute: Gyeonggi, Korea, 2013; pp. 23-27.

31. Park, J.W. 3R Policies of Korea; Ministry of Environment: Seoul, Korea, 2009. Available online: https://www.kdi.re. kr/kdi_eng/publications/reports.jsp (accessed on 15 November 2019).

32. Annual Report of Environmental Protection Department of Hong Kong; Ministry of Environment of South Korea: Seoul, Korea, 2018.

33. Ministry of Environment, Government of the Republic of Korea. 1997 to 2015. Current Status of Waste Generation and Treatment (in Korean). Available online: http://eng.me.go.kr/eng/web/index.do?menuId=394 (accessed on 15 November 2019).

34. Chen, C.; Hellmann, J.; Berrang-Ford, L. A global assessment of adaptation investment from the perspectives of equity and efficiency. Mitig. Adapt. Strat. Glob Chang. 2018, 23, 101-122. [CrossRef]

35. Samsung's, LG's Marketing Costs Rise in 2016 Amid Heightened Competition. Yonhap News Agency, 2017. Available online: http://english.yonhapnews.co.kr/news/2017/04/05/0200000000AEN20170405001800320. html?input=rss (accessed on 2 March 2020).

36. Samsung Corporation Website. Available online: https://www.samsung.com/ca/aboutsamsung/sustainability/ environment/resource-efficiency/ (accessed on 17 February 2020).

37. Beinat, E.; Nijkamp, P. Multi-Criteria Evaluation in Land Use Management; Kluwer Academic Publishers: Dordrecht, The Netherlands, 1998; pp. 56-68.

38. Brav, A.; Graham, J.R.; Harvey, C.R.; Michaely, R. Payout policy in the 21st century. J. Financ. Econ. 2005, 77, 483-527. [CrossRef]

39. Shvetsova, O.A.; Rodionova, H.A.; Epstein, M.Z. International Evaluation of Investment Projects under Uncertainty: Multi-Criteria Approach Using Interval Data. Int. J. Entrep. Sustain. Issues 2018, 7, 46-68.

40. Brigham, E.F.; Ehrhardt, M.C. Financial Management: Theory and Practice; South-Western College Publishing: Cincinnati, OH, USA, 2015; pp. 23-35.

41. Vedernikov, Y.V.; Mogilenko, V.V. Scientific and methodical apparatus of vector preference for complex technical systems characterized by quality indicators specified in a limited-indefinite form, Issues of Modern Science and Practice. System Analysis. Autom. Manag. 2011, 32, 81-96.

42. Rodionova, E.A.; Trifonova, N.V.; Epstein, M.Z.; Shvetsova, O.A. Multicriterial approach to estimation of economic efficiency based on regional innovative cluster. In Proceedings of the 20th IEEE International Conference on Soft Computing and Measurements, SCM, St. Petersburg, Russia, 24-26 May 2017; pp. 89-97.

43. Rodionova, E.A.; Epshtein, M.Z.; Petukhov, L.V. Multivariate evaluation of investment projects based on interval preferences, Scientific and Technical Sheets of the Saint-Petersburg Polytechnic University. Information. Telecommun. Manag. 2013, 169, 141-148.

44. Rodionova, E.A.; Shvetsova, O.A.; Michael, Z.E. Multicriterial Approach to Investment Projects: Estimation under Risk Conditions. Revista Espacios 2018, 39, 28-44. 
45. Bukhvalov, A.V.; Bukhvalov, V.V.; Idelson, A.V. Financial Calculations for Professionals; BHV-Petersburg: St. Petersburg, Russia, 2011; pp. 78-90.

46. Grierson, D.E. Pareto multi-criteria decision making. Adv. Eng. Inform. 2008, 22, 371-384. [CrossRef]

47. Gurumurthy, A.; Kodali, R. Multi-criteria decision-making model for the justification of lean manufacturing systems. Int. J. Manag. Sci. Eng. Manag. 2013, 3, 100-118. Available online: http://www.worldacademicunion. com/journal/MSEM/msemVol03No02paper02 (accessed on 12 December 2019). [CrossRef]

48. Hayashi, K. Multicriteria analysis for agricultural resource management: A critical survey and future perspectives. Eur. J. Oper. Res. 2000, 122, 486-500. [CrossRef]

49. Jelnova, C.V. Analysis of the Practice of Decision-Making in the Field of Investment Policy, Contemporary Economic Issues 4, 2013. Available online: http://economic-journal.net/index.php/CEI/article/view/83/70 (accessed on 11 March 2020). [CrossRef]

50. Mardani, A.; Jusoh, A.; Zavadskas, E.K.; Khalifah, Z.; Nor, K. Application of multiple-criteria decision-making techniques and approaches to evaluating of service quality: A systematic review of the literature. J. Bus. Econ. Manag. 2015, 16, 1034-1068. [CrossRef]

51. Mazur, I.I.; Shapiro, V.D.; Olderogge, N.G. Project Management: Practical Allowance for Universities; Omega-L: Moscow, Russia, 2014; pp. 12-17.

52. Kangas, J.; Kamgas, A. Multiple criteria decision support methods in forest management. An overview and comparative analyses. In Multi-Objective Forest Planning; Pukkala, T., Ed.; Kluwer Academic Publishers: Dordrecht, The Netherlands, 2002; pp. 37-70. [CrossRef]

53. Orlovsky, S.A. Problems of Decision Making with Fuzzy Source Information; Nauka: Moscow, Russia, 1981; pp. 78-89.

54. Serguieva, A.; Hunter, J. Fuzzy interval methods in the investment risk appraisal. Fuzzy Sets Syst. 2014, 142, 443-466. [CrossRef]

55. Stoyanova, E.S.; Krylova, T.B. Financial Management: Theory and Practice; Perspectiva: Moscow, Russia, 2006; pp. 56-78.

56. Olson, D. Decision Aids for Selection Problems; Springer: New York, NY, USA, 1995. [CrossRef]

57. Minakova, L.V.; Anikanov, P.V. Modelling of area of possible results of the innovative investment project. Contemp. Econ. Issues 2013, 1, 23-28.

58. Parrino, R.; Kidwell, D.; Bates, T. Essentials of Corporate Finance; Wiley: New York, NY, USA, 2014; pp. 55-57.

59. Roy, B. Problems and Methods of Solutions in Problems with Many Objective Functions, in Analysis Questions and Decision-Making Procedures; MIR: Moscow, Russia, 1976; pp. 20-58.

60. Saaty, T.L. Multi-Criteria Decision Making: The Analytic Hierarchy Process; RWS Publications: Pittsburgh, PA, USA, 1990; pp. 12-18.

61. Keshavarz Ghorabaee, M.; Zavadskas, E.K.; Olfat, L.; Turskis, Z. Multi-criteria inventory classification using a new method of evaluation based on distance from average solution (EDAS). Informatica 2015, 26, 435-451. [CrossRef]

62. Opricovic, S.; Tzeng, G.H. Compromise solution by MCDM methods: A comparative analysis of VIKOR and TOPSIS. Eur. J. Oper. Res. 2004, 156, 445-455. [CrossRef]

63. Wang, J.J.; Jing, Y.Y.; Zhang, C.F.; Zhao, J.H. Review on Multi-Criteria Decision Analysis Aid in Sustainable Energy Decision-Making. Renew. Sustain. Energy Rev. 2009, 13, 2263-2278. [CrossRef]

64. Zare, M.; Pahl, C.; Rahnama, H.; Nilashi, M.; Mardani, A.; Ibrahim, O.; Ahmadi, H. Multi-criteria decision-making approach in e-learning: A systematic review and classification. Appl. Soft Comput. 2016, 45, 108-128. [CrossRef]

65. Tarp, S. Theory-based lexicographical methods in a functional perspective. An overview. Lexicographica 2014, 30, 58-76. [CrossRef]

66. Tsoutos, T.; Drandaki, M.; Frantzeskaki, N.; Iosifidis, E.; Kiosses, I. Sustainable energy planning by using multi-criteria analysis application in the Island of Crete. Energy Policy 2009, 37, 1587-1600. [CrossRef]

67. Seitz, N.E.; Ellison, M. Capital Budgeting and Long-Term Financing Decisions; Harcourt Brace College Publishers: Fort Worth, TX, USA, 1999; pp. 45-56.

68. Savchuk, V.P. Evaluation of the Investment Projects' Effectiveness; Phoenix: Moscow, Russia, 2007; pp. 66-78.

69. Syroezhin, I.M. Perfection of the System of Efficiency and Quality Indicators; The Economy: Moscow, Russia, 1980; pp. 78-98. 
70. Prisyach, E.Y.; Shvetsova, O.A. Elements of Innovative Scenario's Development of Waste Management System in Russia. In Proceedings of the 2018 IEEE International Conference in Management of Municipal Waste as an Important Factor of Sustainable Urban Development, WASTE, St. Petersburg, Russia, 4-6 October 2018; pp. 89-93.

71. Shvetsova, O.A.; Suthar, B. Business Trends and Opportunities of South Korea and India Cooperation. In Proceedings of the 2018 International Conference "Quality Management, Transport and Information Security, Information Technologies", IT and QM and IS, St. Petersburg, Russia, 24-28 September 2018; pp. 53-59.

72. Khokhlov, N.V. Risk Management: Practical Allowance for Universities; UNITY-DANA: Moscow, Russia, 2011.

73. Laufman, G. To Have and Have Not; CFO Publishing Corporation: New York, NY, USA, 1998; pp. 78-79.

74. Lukicheva, L.I.; Egorychev, D.N. Decision Making Process in Management; Omega-M: Moscow, Russia, 2016; pp. 99-109.

75. Epstein, M.Z.; Shvetsova, O.A. Development of Innovative Strategies: Comparative Analysis of External and Internal Environments. Revista Espacios 2018, 40, 45-56.

76. National Disaster Recovery Framework Strengthening Disaster Recovery for the Nation; FEMA: Washington, DC, USA, 2016; pp. 78-99.

77. Shvetsova, O.A. Practical and theoretical issues of innovation management in South Korea. Int. J. Innov. Technol. 2017, 4, 78-89.

78. Shvetsova, O.A. Management of small and medium enterprises in global environment. In Proceedings of the IEEE Proceedings of 2nd International Conference on Control in Technical Systems, CTS, St. Petersburg, Russia, 25-27 October 2017; Volume 2017, pp. 45-56.

(C) 2020 by the authors. Licensee MDPI, Basel, Switzerland. This article is an open access article distributed under the terms and conditions of the Creative Commons Attribution (CC BY) license (http://creativecommons.org/licenses/by/4.0/). 